Abstracta Iranicacta Iranica

Revue bibliographique pour le domaine irano-aryen

Volume 37-38-39 | 2018

Comptes rendus des publications de 2014-2016

\title{
Kyle Smith. Constantine and the Captive Christians of Persia: Martyrdom and Religious Identity in Late Antiquity
}

Christelle Jullien

\section{(2) OpenEdition \\ Journals}

Édition électronique

URL : http://journals.openedition.org/abstractairanica/44350

DOI : 10.4000/abstractairanica.44350

ISBN : 1961-960X

ISSN : 1961-960X

Éditeur :

CNRS (UMR 7528 Mondes iraniens et indiens), Éditions de l'IFRI

Référence électronique

Christelle Jullien, « Kyle Smith. Constantine and the Captive Christians of Persia: Martyrdom and Religious Identity in Late Antiquity », Abstracta Iranica [En ligne], Volume 37-38-39 | 2018, document 19, mis en ligne le 30 décembre 2018, consulté le 27 septembre 2020. URL : http://journals.openedition.org/ abstractairanica/44350 ; DOI : https://doi.org/10.4000/abstractairanica.44350

Ce document a été généré automatiquement le 27 septembre 2020.

Tous droits réservés 


\title{
Kyle Smith. Constantine and the Captive Christians of Persia: Martyrdom and Religious Identity in Late Antiquity
}

\author{
Christelle Jullien
}

\section{RÉFÉRENCE}

Kyle Smith. Constantine and the Captive Christians of Persia: Martyrdom and Religious Identity in Late Antiquity. Oakland: University of California Press, 2016, XXIII + $231 \mathrm{p}$.

(Transformation of the classical heritage 57), ISBN 9780520289604.

1 Dans cet ouvrage, l'A. analyse d'une part l'impact historique de la conversion de l'empereur Constantin, motif qui a été à l'origine d'une réflexion sur le rapport au pouvoir au sein des communautés chrétiennes grecques mais aussi syriaques de Mésopotamie, et plus largement au sein des empires byzantin et sassanide; d'autre part, il étudie les élaborations littéraires du personnage dans les récits chrétiens - ce qu'il appelle « les imaginaires ». Dans une première partie, l'A. réexamine les données de la lettre de Constantin à Šābuhr II, conservée dans la Vita Constantini d'Eusèbe ( $1^{\mathrm{e}}$ rubrique et Appendix A). Son authenticité a souvent été remise en question par la critique sans faire l'objet d'un consensus ; l'A. est prêt à lui donner crédit, en insistant sur sa postérité puisqu'elle a été diffusée dans les milieux chrétiens comme une lettre véridique de l'empereur. Pour se démarquer de ses prédécesseurs, Constantin aurait construit un discours de propagande contre leurs actions anti-chrétiennes, posant ainsi les conditions d'un nouveau rapport au pouvoir. Mais il faut souligner aussi que l'image de Constantin campé en empereur chrétien idéal a été renforcée a posteriori par Eusèbe (je renvoie à ce propos à l'étude récente d'Alessandro Barbero, Costantino il vincitore, (Biblioteca Storica), Roma: Salerno, 2016). L'A. affirme que l'adoption du christianisme par Constantin a été considérée par la plupart des chercheurs comme la cause première d'une rupture entre les deux empires romain ("chrétien") et sassanide (zoroastrien) aboutissant à une persécution des chrétiens en Perse - les chrétiens, partageant la 
religion de l'empereur romain, étant perçus comme une "cinquième colonne" en Perse. Rappelons que depuis une dizaine d'années, plusieurs études ont montré que ces accusations d'infidélité politique et de déloyauté des chrétiens à l'égard du roi des rois forment un thème topique qui perdura jusqu'au VII e siècle dans les sources syriaques (nous savons d'ailleurs que le thème hagiographique de la lettre au "César " par les chrétiens de Perse trouve encore un écho dans la littérature épique persane, à travers le Šāhnāme de Ferdowsī par exemple) alors même que la situation des chrétiens en Orient devait évoluer à la suite des définitions conciliaires, des choix christologiques et des positionnements de chacune des communautés ecclésiales. Voir les études d'Antonio Panaino par exemple: "The "Persian" Identity in Religious Controversies. Again on the Case of the "Divided Loyalty" in Sasanian Iran", dans C. Cereti (ed.), Iranian Identity in the Course of History, (Seria Orientale Roma CV. Orientalia Romana 9), Roma, 2010, p. 227-240; et "La Chiesa di Persia e l'Impero Sasanide. Conflitto e Integrazione ", Cristianità d'Occidente e Cristianità d'Oriente (secoli VI-XI), (Settimana di Studio del Centro Italiano di Studi sull'Alto Medioevo 51), Spoleto, 2004, p. 765-869. Pour l'A., les écrivains des siècles postérieurs se seraient appuyés d'une part sur les relations entre Constantin et Šābuhr pour rassurer les communautés au moment des guerres romano-perses, et d'autre part sur une représentation hagiographique de Constantin pour intégrer les chrétiens syro-orientaux dans une communauté supra-frontalière. Cette dernière hypothèse n'est peut-être pas si bien fondée, car la question hérésiologique reste centrale pour comprendre les positionnements des chrétiens visà-vis du pouvoir; de la sorte, les syro-orientaux, circonscrits dans les limites de l'empire sassanide, n'avaient pas d'autre choix que la loyauté à l'égard du roi des rois.

2 La seconde partie analyse plus explicitement les relations entre guerre et persécution à travers deux exemples: les Exposés d'Aphraate le sage perse, et le cycle narratif du Martyre et de l'Histoire du primat de l'Église d'Orient Siméon Bar Șabba'ē ( $4^{e}$ rubrique) que l'A. a publiés en 2014. Selon lui, ce fut sans doute par la diffusion du cycle sur Siméon que s'élabora le lien de cause à effet entre la disparition de Constantin, considéré comme le protecteur des chrétiens de Perse, et une persécution de Šābuhr, favorisant des développements narratifs rattachant les chrétiens de Perse à une communauté universelle supra-frontalière. L'A. remet en question ce qu'il appelle la " soi-disant persécution » de Šābuhr II en la réduisant à une affaire de fiscalité plutôt que de religion, Siméon ayant refusé de soumettre sa communauté à un impôt supplémentaire. Après avoir reconsidéré les sources de la guerre romano-perse sous Šābuhr II, et donné une nouvelle lecture de la bataille de Nisibe (première partie, $2^{\mathrm{e}}$ et $3^{\mathrm{e}}$ rubriques), il commente un extrait pris aux Hymnes d'Éphrem contre Julien montrant la neutralité de Šābuhr à l'endroit des lieux de culte chrétiens qu'il aurait épargné. Peut-être eut-il été utile de consulter l'étude de P. Wood, We Have no King but Christ. Christian Politic Thought in Greater Syria on the Eve of the Arab Conquest (c. 400-585), (Oxford Studies in Byzantium), Oxford, 2010. Signalons aussi la nouvelle édition de ce texte aux Sources chrétiennes par D. Cerbelaud, Éphrem de Nisibe. Hymnes contre les hérésies. Hymnes contre Julien. II: Hymnes contre les hérésies XXX-LVI. Hymnes contre Julien, (Sources chrétiennes 59), Paris, 2017. Notons que, curieusement, Éphrem ne parle pas de la situation des chrétiens de l'empire sassanide; son intention d'écriture est claire: montrer une prise de distance des communautés chrétiennes avec l'autorité politique qui est décrite comme le bras exécutif de la Providence divine, l'émissaire de Dieu en faveur des chrétiens, et l'artisan du châtiment divin contre le péché des habitants de la ville de Nisibe. Une telle description est assez topique et se retrouve par exemple plus 
tard chez Procope dans sa description de la prise d'Amid par le Sassanide Kawād I ${ }^{\text {er }}$ en 502 (De Bello Persico I, 7). Sur le qarugbed Pusiy, cf. C. Jullien, F. Jullien, Apôtres des confins. Processus missionnaires chrétiens dans l'empire iranien (Res Orientales XV), Bures-sur-Yvette, 2002, p. 161-163. La "mémoire de Constantin" ( $6^{\mathrm{e}}$ rubrique) dans les sources plus tardives, et spécialement dans le corpus des Actes des martyrs perses, donne un regard neuf sur le façonnement et les manipulations de traditions par les chrétiens syriaques au service de la construction de leur identité, dans la mouvance de l'étude d'Alexander M. Schilling, Die Anbetung der Magier und die Taufe der Sasaniden. Zur Geistesgeschichte des iranischen Christentums in der Spätantike, (CSCO 621, Subsidia 120), Louvain, 2008.

3 À travers l'analyse de diverses sources grecques, latines et syriaques, parfois largement postérieures à l'époque considérée, l'ouvrage offre une nouvelle appréhension des relations entre communautés chrétiennes et leurs autorités politiques référentes entre Byzance et la Perse, en réexaminant les distorsions hagiographiques et historiographiques pour dégager les sources des représentations identitaires en milieu syriaque. Il s'achève sur une bibliographie et des indices fort utiles, ainsi que trois traductions de novo en appendice : l'extrait de la Vie de Constantin par Eusèbe de Césarée (IV, 8-14) où se trouve insérée la lettre de Constantin à Šābuhr; le Martyre des captifs du Bēth-Zabdaï (BHO 375 ; AMS II, 316-324); et la Passion du rišdayra Baršebya avec dix de ses frères en religion et un mage (BHO 146, AMS II, 281-284).

\section{AUTEURS}

\section{CHRISTELLE JULLIEN}

CNRS, Mondes iranien et indien, Paris 